\title{
Spinocerebellar ataxia type 1
}

INSERM

\section{Source}

INSERM. (1999). Orphanet: an online rare disease and orphan drug data base.

Spinocerebellar ataxia type 1. ORPHA:98755

Spinocerebellar ataxia type 1 (SCA1) is a subtype of type I autosomal dominant cerebellar ataxia (ADCA type I; see this term) characterized by dysarthria, writing difficulties, limb ataxia, and commonly nystagmus and saccadic abnormalities. 